OPEN ACCESS

Edited by:

Gerrit C. Van Der Veer,

University of Twente, Netherlands

Reviewed by:

Christos Troussas,

University of West Attica, Greece

Ernest Afari,

University of Bahrain, Bahrain

*Correspondence:

Xiaoquan Pan

pxq@zjnu.cn

Specialty section:

This article was submitted to

Educational Psychology,

a section of the journal

Frontiers in Psychology

Received: 31 July 2021 Accepted: 22 November 2021 Published: 16 December 2021

Citation:

Pan X and Chen W (2021) Modeling Teacher Supports Toward

Self-Directed Language Learning Beyond the Classroom: Technology

Acceptance and Technological

Self-Efficacy as Mediators.

Front. Psychol. 12:751017.

doi: 10.3389/fpsyg.2021.751017

\section{Modeling Teacher Supports Toward Self-Directed Language Learning Beyond the Classroom: Technology Acceptance and Technological Self-Efficacy as Mediators}

\author{
Xiaoquan $\mathrm{Pan}^{1 *}$ and Wei Chen ${ }^{2}$ \\ ${ }^{1}$ Xingzhi College, Zhejiang Normal University, Jinhua, China, ${ }^{2}$ College of Foreign Languages, Zhejiang Normal University, \\ Jinhua, China
}

This study explored the contributions of teacher supports toward students' selfdirected language learning beyond the classroom and investigated whether technology acceptance and technological self-efficacy could be the mediators between teacher supports and students' self-directed language learning in a sample of Chinese undergraduate students. A total of 197 freshmen students in one university in Eastern China participated in the questionnaires concerning teacher supports, technology acceptance, technological self-efficacy and self-directed language learning. The study highlighted the results: (1) perceived usefulness mediated the relationship between teacher affective supports and students' self-directed language learning as well as the relationship between teacher capacity supports and students' self-directed language learning; (2) technological self-efficacy mediated the relationship between teacher affective supports and students' self-directed language learning as well as the relationship between teacher behavior supports and students' self-directed language learning; and (3) perceived easy of use had no noticeable mediating functions, but exerted an indirect influence on students' self-directed language learning. These findings extended previous researches by considering both the external factors (i.e., teacher supports) and the internal factors (i.e., technology acceptance and technological selfefficacy) of influencing students' self-directed language learning, thereby contributing to enhancing our understanding of the joint drive of the inherent and extrinsic power mechanisms. This study indicated the significance of elevating teachers' awareness of the substantial supports in enhancing students' self-directed language learning beyond the classroom and would inform that the future research on teachers' compliance in relation to technology use be converted from institutional mandates into teachers' conscientious behaviors.

Keywords: self-directed language learning, teacher supports, technology acceptance, technological selfefficacy, English language learning 


\section{INTRODUCTION}

Technology with its fast-moving pace has pervaded the educational aspects in recent years (Garrison and Akyol, 2009; Hung et al., 2010), thus enabling students' self-initiated, selfconstructed, and self-monitored learning experiences in a newlyconstructed technology-based ecology of language learning (Lai and Gu, 2011; Reinders and White, 2011). Online learning, E-learning, M-learning and other informal technological learning approaches provide students with more chances to explore selfdirected learning ways (King and He, 2006; Zandi et al., 2014; Hsu, 2016; Huang et al., 2020; Pan, 2020). However, in spite of the booming attention and development on technological teaching approaches in educational landscapes, the enthusiasm and motivation of students to conduct technology-based self-directed language learning need further exploring (Lai et al., 2018). Furthermore, although the technology has become ubiquitous and demonstrated varieties of advantages, how it exerts its strengths and facilitates students' self-initiated use of technology for language learning is still a sophisticated problem (Chen, 2018; Huang et al., 2019a). Thus, an increasing number of scholars are arguing for the need to provide learners with external support to enhance effective use of technology for language learning (Cohen and White, 2008; Hubbard and Romeo, 2012; Lai et al., 2016). Jeyaraj et al. (2006) found that school factors such as teachers' influence on technology adoption decisions significantly affected students' technology-based selfdirected learning. According to Huang et al. (2019b), teachers in China are considered as superiors and vital roles in supervising students' learning, as China is recognized by its collectivist culture where hierarchy is highly appreciated (Hofstede, 2008). Researchers also found that students could increase the frequency of self-initiated use of technology for language learning as a consequence of teachers' active encouragement and suggestions (Deepwell and Malik, 2008; Lai et al., 2016). Carson and Mynard (2012) further identified that some categories of teacher supports such as pedagogical suggestions, curriculum expectancy contributed to more favorable perception of use of technology and led to greater awareness of language learning potentials. As Lai et al. (2017) pointed out, "given the myriad of ways in which teachers shape language learners' perceptions of and self-directed use of technology, it is critical to understand how these different types of teacher behaviors interact with other psychosocial factors to influence language learners' self-directed use of technology for learning outside the classroom" (p. 1107). Research evidence has built up in support of teachers' supervising behaviors in facilitating students' willingness to study beyond the classroom (Hagger and Chatzisarantis, 2012). Therefore, teacher supports constitute a multitude of cognitive and non-cognitive functions for stimulating students' self-directed language learning. In addition to the enhanced external factors that affect students' technology-based self-directed language learning, various psychological and sociocultural factors that could influence students' adoption of technological resources for language learning were explored (Bailly, 2011; Lai et al., 2016). For instance, the study of Mew and Honey (2010) indicated that technological learning motivation significantly influences students' intention to use online learning websites, technologyrelated facilities and their personal technology application. Among the widely used, multidimensional constructs of perceived behavioral control, technological self-efficacy was considered as the dominant determinant of the intention of using the technology (Teo, 2009; Teo and van Schaik, 2012). However, despite some researches being conducted from either external or internal perspectives, there are still few studies to investigate the influence from both the internal and external factors on students' self-directed language learning. Therefore, this study aimed to explore how the external factors (i.e., teacher supports) influenced students' self-directed language learning and whether students' internal factors (i.e., technology acceptance and technological self-efficacy) would mediate the relationship between teacher supports and students' self-directed language learning. The present study's main contribution lies in enhancing our understanding of the potential roles that teachers could play in supporting students' self-directed use of technology for learning outside the classroom and the joint drive of the inherent and extrinsic power mechanisms.

\section{LITERATURE REVIEW}

\section{Technology Acceptance Model}

Davis (1989) proposed the technology acceptance model (TAM) on the basis of the theory of reasoned action (TRA) raised by Fishbein and Ajzen (1975). "The Technology Acceptance Model (TAM) has been found to be efficient in explaining user behavior across a broad range of end-user computing technologies and user populations" (Teo, 2011, p. 2433). In the TAM, Davis (1989) identified perceived usefulness (PU) and perceived easy of use (PEU) to be the antecedent variables to affect individual's intentions and behaviors to use technology, as individual's behavior intention is posted to be affected by the direct and indirect effects of PU and PEU. Perceived usefulness (PU) manifested learners' expected overall outcome of technology adoption, whereas perceived easy of use (PEU) dominantly pertained to those impacts associated with the process of using technology (Teo, 2011). Perceived usefulness was consistently considered to be the most robust predictor of students' technology adoption for learning intentions (Yousafzai et al., 2007; Teo, 2011, 2015). Previous research also found that students' preference and tendency to conduct technology-based learning was determined by their perception of the potential usefulness of technological resources (Clark et al., 2009; Lai and $\mathrm{Gu}, 2011)$. Therefore, perceived usefulness was involved as a significant predictor in our hypothesized model. Additionally, in response to Davis's (1989) conforming perceived ease of use as an antecedent of perceived usefulness, the associations between the two have been further explored. For instance, perceived easy of use (PEU) was examined to have a positive effect on perceived usefulness (PU) (Liaw and Huang, 2003; Teo, 2009; Wong et al., 2012). In the TAM model, "these two constructs influence the user's Attitude toward using the system (AT), which in its turn influences the Behavioral Intention to use the system (BI), which determines at the endpoint the 
actual system use where people use the technology" (Papakostas et al., 2021, p. 2). The new integrated TAM model proposed by Venkatesh and Bala (2008) takes into consideration user's general beliefs (i.e., perceptions of external control, technological self-efficacy) about computer applications. In recent years, the TAM has been widely utilized in many other areas such as economy and pedagogy. In the educational landscape, there are lots of empirical researches to connect pedagogical support for the use of TAM. For instance, Liaw et al. (2007) found out that students' technology acceptance is the key factors for technology-based learning. Hsieh et al. (2017) also proposed that the technology acceptance was the prerequisite for students to learn knowledge via using technology. Besides, there are further studies exploring the associations between learner's technology acceptance and other factors such as self-efficacy (Cho and Kim, 2013). Lai (2015) investigated the relationship between internal variables of technology acceptance and learner's intention to use technology in language learning context. Currently, TAM has been identified as a stable and parsimonious theoretical model for applications in educational contexts, such as mobile game-based learning as a solution in COVID-19 era (Krouska et al., 2021), social networking-based learning (Troussas et al., 2021), the integration of Augmented Reality (AR) in course training (Papakostas et al., 2021), the digital learning technologies (Sprenger and Schwaninger, 2021), and language teachers' adoption of educational technology (Sun and Mei, 2020). However, although there are a lot of studies to explore the technology acceptance model and connect this model with educational issues, there are still few researches to further investigate how learners' technology acceptance influence language learning in mainland China and whether technology acceptance can be the mediating variable to influence students' self-directed language learning.

\section{Teacher Supports}

Teachers significantly shape the quality of students' learning experiences by affecting students' cognitive, affective and social learning behaviors (Farmer et al., 2011). As a significant social agent, teachers play a critical role in helping students develop autonomy of technology-based language learning beyond class (Reinders and Darasawang, 2012). Knowles (1989) defined self-directed learning as "a process in which individuals take the initiative, with or without the help from others, in diagnosing their learning needs, formulating goals, identifying human and material resources, choosing and implementing appropriate learning strategies and evaluating learning outcomes"(p. 18). Extant literature has indeed approached self-directed learning from the perspectives of the personal attribute (e.g., individuals' propensity, willingness and capacity to conduct learning behaviors; Garrison, 1997), the process (Salleh et al., 2019), and the context (Song and Hill, 2007). In light of these particular research lines, the function of teacher supports should be manifested in helping students to be academically, professionally and psychologically empowered, motivating students' personal attribute, and facilitating students' selfinitiated use of technological resources to autonomously clutch the reins of self-directed learning process. According to Fagerlund (2012), in-class technological instructions and supports conducted by teachers will be learned and continued by students outside the classroom. Based on students' exposure to engaging learning experience and environments, Lai and $\mathrm{Gu}$ (2011) found that it was more possible for students to use the technologies that teacher had used in class. Accordingly, both the quantity and quality of students' autonomous use of technology to learn language are deeply influenced by teachers' opinions and behaviors (e.g., Arbaugh, 2000; Margaryan and Littlejohn, 2010; Imlawi et al., 2015; Hao et al., 2017). Carson and Mynard (2012) identified different teacher supports that facilitated students self-directed language learning: (1) by raising students' technological awareness through expounding the advantages of technology in language learning; (2) by offering technological resources/strategies to help students slash the difficulties of discovering useful resources online; and (3) by organizing varieties of technological activities to activate students technological interests. Researches have reported that the guidance and support from teachers drove students' engagement in technology-based self-directed language learning (Ertmer et al., 2012), helped students incorporate learning resources/activities into their learning ecology (Lai et al., 2014), and facilitated students to utilize technology as learning tools (McLoughlin and Lee, 2010). Due to different characteristics and functions of teacher supports, researchers resorted to the classification of teacher supports so as to definitely depict the associations of teacher supports and students' learning behaviors. Three categories of teacher supports of technology were posited, respectively, teacher affective supports (Carson and Mynard, 2012; Lai, 2015), teacher behavior supports (Deepwell and Malik, 2008; Gray et al., 2010; Fagerlund, 2012; Lai, 2013) and teacher capacity supports (Fagerlund, 2012; Lai, 2015). Teacher affective supports (TAS) mainly refer to teacher behaviors which can provide students with the basic knowledge of the strengths of technology as well as the encouragement of using technology in language learning (Xia and Lee, 2000). Teacher behavior supports (TBS) involve teachers' capacities of organizations and management that can help students participate in activities and tasks involving technologies (Ertmer, 2005). Teacher capacity supports (TCS) mainly help students to get some useful technological resources and tell them how to select and use technological resources effectively (Gallivan et al., 2005). The current literature abounds in discussions on the impact of teacher supports on promoting students' language learning. However, the internal mechanism between teacher supports and students' technology-based self-directed language learning beyond the classroom needs to be further explored.

\section{Technological Self-Efficacy}

Bandura's (1997) notion of self-efficacy highlighted how one individual's self-regulatory process influence his or her behavior, and thereby self-directed learning manifested the degree to which students are "metacognitively, motivationally, and behaviorally active participants in their own learning process" (Zimmerman, 1986, p. 308). Researchers for decades have been conducting studies in understanding the especially important role that self-efficacy plays in connection with self-directed learning. 
Research evidence shows that self-efficacy has strong relationship with one's expectations and interests in learning, including the enhancement of one's confidence (Zuffianò et al., 2013), the improvement of the degree of one's efforts on tasks (Abali Ozturk and Sahin, 2015), and the perceived responsibility for learning (Kitsantas and Zimmerman, 2009). Further, research result indicated that students with higher self-efficacy demonstrated a higher volley of inspirations and motivations than lower selfefficacy students, and tended to spend more time on their studies (Bassi et al., 2007). In the study of Zuffianò et al. (2013), self-efficacy has academically been viewed to possess the function to allow students to experience the feeling of worth and confidence which can contribute to students' better learning performance. In the wake of network technology, the phenomenon of combining the self-efficacy with technology is triggered. Based on the concept of self-efficacy, technological self-efficacy mainly refers to one's perception of his or her capacities to use technology-connected tools or resources to conduct and finish some tasks (Keengwe, 2007). Among the key motivation constructs associated with students' technology adoption for self-directed learning, technological self-efficacy is identified as the important factor that affects one's use of technology (Yesilyurt et al., 2016). In this study, technological self-efficacy is characterized as students' perception of their capabilities to utilize technology-related tools and sites to conduct learning behaviors so as to achieve intended learning outcome (Bandura, 1997; Keengwe, 2007). Researchers have verified a significant positive influence of technological self-efficacy on technology acceptance and utilization (Celik and Yesilyurt, 2013) and regarded technological self-efficacy as a proxy of individuals' control beliefs in technology use (Venkatesh and Davis, 1996). Researchers have also found that technological selfefficacy significantly affects students' behavioral preferences to use technological tools and their perceptions of the usefulness of technology for learning (Keengwe, 2007; Mew and Honey, 2010). More specifically, in learning process, technological self-efficacy constitutes a significant psychological homeostasis that students utilize to help develop their habits of using technology and their perceptions of the usefulness of technology in learning (Keengwe, 2007; Mew and Honey, 2010). Therefore, technological self-efficacy noticeably affects students' technologyrelated language learning behaviors. As one of the students' causal attributions regarding their technology-based self-directed learning, this variable of technological self-efficacy should be considered and examined, especially in the technology-correlated educational context.

While a burgeoning research on self-directed language learning, self-efficacy, and sources of self-efficacy has been conducted (Sundqvist, 2011; Su et al., 2018), there remains a lack of research examining both the external and internal variables which influence students' awareness and perceptions of technology acceptance and technological self-efficacy in cultivating and enhancing their behaviors of self-directed language learning. Based on the previous researches, teachers as the important social agents have the irreplaceable roles in directing and facilitating students' self-directed language learning (Davis, 2003). Therefore, this study aims to connect more variables (e.g., teacher support, technology acceptance, technological self-efficacy) to explore their respective influence on students' self-directed language learning and the potential relationships.

\section{Problem Statement and Hypothesis}

Informed by recent new visions in the study of technology-based self-directed language learning discussed above, two research questions are specified below:

Question 1: How do teacher supports contribute to students' technology-based self-directed language learning beyond the classroom?

Question 2: Will technology acceptance and technological self-efficacy mediate this relationship?

Thereby, this research aimed to test the following nine hypotheses (Figure 1):

H1: Teacher affective support (TAS) correlates with students' self-directed language learning (SDLL) via perceived usefulness (PU).

H2: Teacher capacity support (TCS) correlates with students' self-directed language learning (SDLL) via perceived usefulness (PU).

H3: Teacher behavior support (TBS) correlates with students' self-directed language learning (SDLL) via perceived usefulness (PU).

H4: Teacher affective support (TAS) correlates with students' self-directed language learning (SDLL) via perceived easy of use (PEU).

H5: Teacher capacity support (TCS) correlates with students' self-directed language learning (SDLL) via perceived easy of use (PEU).

H6: Teacher behavior support (TBS) correlates with students' self-directed language learning (SDLL) via perceived easy of use (PEU).

H7: Teacher affective support (TAS) correlates with students' self-directed language learning (SDLL) via technological self-efficacy (SE).

H8: Teacher capacity support (TCS) correlates with students' self-directed language learning (SDLL) via technological self-efficacy (SE).

H9: Teacher behavior support (TBS) correlates with students' self-directed language learning (SDLL) via technological self-efficacy (SE).

\section{METHODOLOGY}

\section{Participants and Procedure}

Participants were freshmen students at a large comprehensive university in Eastern China who were taking compulsive college 


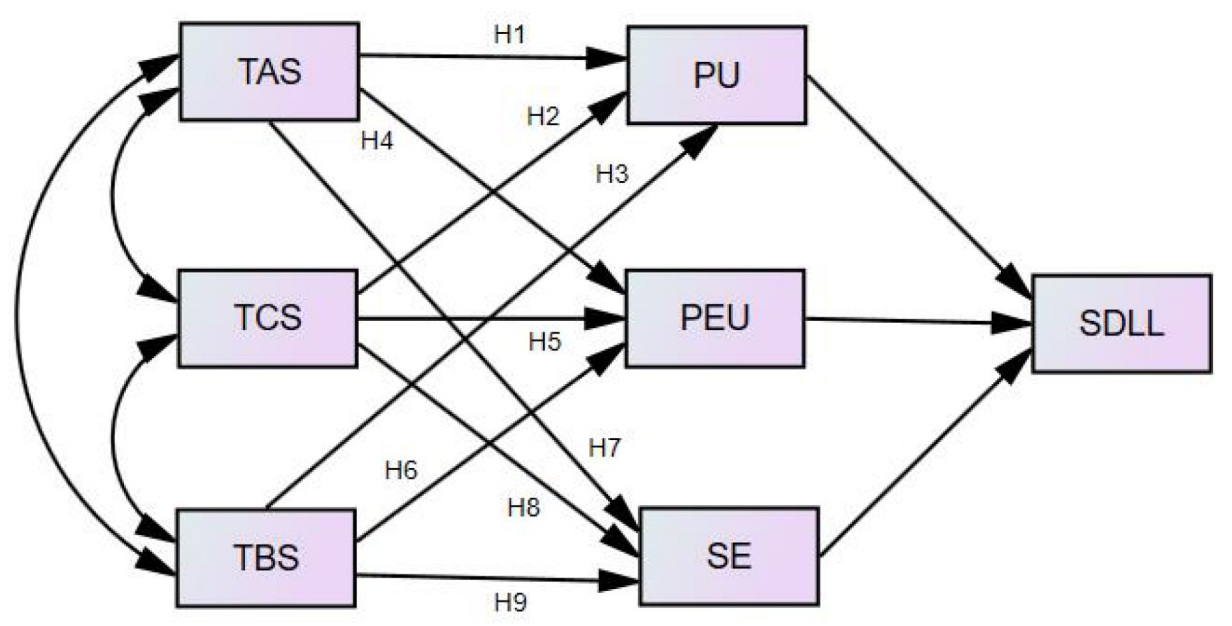

FIGURE 1 | The hypothesis model.

English courses at the time of this study. Currently, the advanced network technology has been applied in college English teaching and learning in accordance with the innovation of college English course. Totally 201 freshmen students voluntarily participated in the survey and were told of their rights to decline. Questionnaires were distributed to the participants on the spot at the class interval of college English course and collected immediately after completion. After consent, participants were briefed several measures of the questionnaire and completed anonymously within $10 \mathrm{~min}$. A total of 197 valid questionnaires were retained after discarding incomplete questionnaires. Of the valid participants, 71 were males $(36 \%)$ and 126 were females $(64 \%)$, with an average age of 19 (SD = 1.45). Noticeably, the equipped network technology in this university is accessible to all students, offering them good facilities to independently conduct self-directed language learning beyond the classroom. Hence, the experiences of the participants' technology adoption for self-directed language learning are representative of what most language learners in this university would experience.

\section{Measures}

The questionnaire items which were adapted and validated from various published sources were used to assess teacher supports (Lai, 2015), technology acceptance (Davis, 1989; Moore and Benbasat, 1991; Taylor and Todd, 1995; Venkatesh and Davis, 2000; Ajzen, 2002), technological self-efficacy (Keengwe, 2007; Celik and Yesilyurt, 2013) and self-directed language learning (Jansen and Janssen, 2017) respectively. Each questionnaire item was measured on a 5-point Likert Scale, ranging from 1 (strongly disagree) to 5 (strongly agree). Higher scores indicated higher perceptions of teacher supports, technology acceptance, technological self-efficacy and self-directed language learning.

\section{Teacher Supports}

Teacher supports were measured in three scales: teacher affective supports (four items, e.g., My English teacher encourages us to use technology for language learning outside the classroom), teacher behavior supports (four items, e.g., My English teacher assigns assignments that are based on or involve the use of online resources or tools), and teacher capacity supports (four items, e.g., My English teacher shares with us useful technological resources/sites/tools for language learning outside the classroom). The Cronbach alpha values of teacher affective supports, teacher behavior supports and teacher capacity supports are $0.916,0.89$, and 0.888 , and Kaiser-MeyerOlkin (KMO) values for validity are $0.846,0.797$, and 0.803 , respectively, indicating a good reliability and validity.

\section{Technology Acceptance}

Technology acceptance was measured using two scales: perceived usefulness (five items, e.g., I find technologies useful in language learning) and perceived ease of use (five items, e.g., I find it easy to select and find appropriate technological tools needed to enhance language learning). As the Cronbach alpha values of perceived usefulness and perceived ease of use are 0.915 and 0.857, respectively, and Kaiser-Meyer-Olkin (KMO) values for validity are 0.886 and 0.748 , the scale has a good reliability and validity.

\section{Technological Self-Efficacy}

Students' technological self-efficacy included five items, e.g., I have the confidence to be proficient in using technology when learning English independently. The Cronbach alpha value of technological self-efficacy is 0.909 and Kaiser-Meyer-Olkin (KMO) value for validity is 0.852 , indicating that the scale has a good reliability and validity.

\section{Students' Self-Directed Language Learning}

Students' self-directed language learning included four items, e.g., I like self-directed English learning outside the classroom. The Cronbach alpha value of students' self-directed language learning is 0.917 and Kaiser-Meyer-Olkin (KMO) value for 
validity is 0.853 , thereby indicating that the scale has a good reliability and validity.

\section{Method of Data Analysis}

Firstly, SPSS21.0 was used to analyze the reliability and the validity of each variable (i.e., teacher supports, technology acceptance, technological self-efficacy and students' self-directed language learning). Secondly, data were analyzed using structural equation modeling (SEM) via Amos 21.0, including the examining of measurement model and the structural part of the SEM (Teo et al., 2016). Following the recommendations by $\mathrm{Hu}$ and Bentler (1999), the model fit was tested by using several goodness-off it indexes, including the ratio of the chi-square to its degrees of freedom $\left(\mathrm{X}^{2} / \mathrm{df}\right)$, RMSEA, SRMR, CFI, and TLI. By Hair et al. (2010), values of $\mathrm{X}^{2} / \mathrm{df}(<3)$, CFI $(>0.90)$, TLI $(>0.90)$, RMSEA $(<0.08)$ and SRMR $(<0.08)$ are reflective of a good fit. In addition, the significance of the mediation effects was assessed using the bias-corrected percentile bootstrap method (Hayes, 2013), computing the confidence interval (CI) for the mediated effect. When zero is not in the CI, it indicates the significance of the indirect effect.

\section{RESEARCH RESULTS}

\section{Descriptive Results and Correlations}

As is shown in Table 1, the mean values of 7 variables varied from 3.27 to 3.88 , indicating participants' positive response to the variables in the questionnaire. The standard deviations varied from 0.78 to 1.01 , which was indicative of a narrow spread of participants' responses.

Tables 2, 3 present that all the measures had good reliabilities (Cronbach's alpha ranged from 0.857 to 0.917). Pearson correlation matrices for the relations between variables show that there were noticeable correlations among the study variables. As shown in Table 2, TCS and TAS had a relatively high correlation $(r=0.826)$, so collinearity variance inflation factors (VIFs) were calculated to examine potential multicollinearity problems. The VIF scores ranged between 1.832 and 4.361 $($ all $<5$ ), which indicated that the estimation of the regression coefficients would not be affected by multicollinearity problems (Montgomery et al., 2001).

TABLE 1 | Descriptive statistics of study variables.

\begin{tabular}{lccccc}
\hline & N & Minimum & Maximum & Mean & SD \\
\hline PU & 197 & 1 & 5 & 3.79 & 0.89 \\
PEU & 197 & 1 & 5 & 3.88 & 0.78 \\
TAS & 197 & 1 & 5 & 3.76 & 0.86 \\
TCS & 197 & 1 & 5 & 3.80 & 0.85 \\
TBS & 197 & 1 & 5 & 3.45 & 0.91 \\
SE & 197 & 1 & 5 & 3.79 & 0.90 \\
SDLL & 197 & 1 & 5 & 3.27 & 1.01 \\
\hline
\end{tabular}

PU, perceived usefulness; PEU, perceived ease of use; TAS, teacher affective supports; TCS, teacher capacity supports; TBS, teacher behavior supports; SE, technological self-efficacy; SDLL, self-directed language learning.

\section{Measurement Model}

Confirmatory factor analysis (CFA) was conducted to assess the fitness of this measurement model. Firstly, to assess the discriminant validity, the square root of AVE for each construct was tested. "If the square root of the AVE of a construct was greater than the off-diagonal elements in the corresponding rows and columns, this suggests that a construct is more strongly correlated with its indicators than with the other constructs in the model thus suggesting the presence of discriminant validity" (Teo, 2011, p. 2436). Table 2 demonstrated that this measurement model established the discriminant validity, as the square root of AVE (shown in parentheses along the diagonal) of each construct is higher (0.740-0.859) than corresponding correlation values for that variable in all cases. Secondly, the convergent validity of the measurement model was tested by examining the reliability of each item through its factor loading and assessing the construct reliability by the Cronbach's alpha, and average variance extracted (AVE), t-value (C. R. > 2) and S. E. value $(>0)$ of parameter estimation. Teo and van Schaik (2012) suggested the standardized factor loadings exceed 0.7, and average variance extracted (AVE) by each construct exceed 0.50 . By these criteria, Table 3 indicated good convergent validity of this measurement model. In addition, Table 3 indicated that, except for PEU1, the standardized factor loadings for all the study constructs exceeded the minimum of 0.70 , suggesting good construct validity. PEU1 was not excluded from further analysis because it was statistically significant.

\section{Path Analysis Testing the Hypothesized Model}

Grounded on the previous researches (e.g., Hu and Bentler, 1999; Marsh et al., 2004), this study examined the model fit using the root mean square error of approximation (RMSEA), the standardized root mean square residual (SRMR), comparative fit index (CFI), and the Tucker-Lewis index (TLI). A good model is indicated by RMSEA $<0.08$, SRMR $<0.06$, and CFI and TLI $>0.90$.

As is shown in Table 4, the unrevised model didn't significantly satisfy the fitting standard values. According to the modification indices in AMOS 21.0, The M. I. values of the paths of technological self-efficacy $(\mathrm{SE}) \rightarrow$ perceived easy of use (PEU), perceived easy of use $(\mathrm{PEU}) \rightarrow$ technological selfefficacy (SE) and teacher behavior supports (TBS) $\rightarrow$ self-directed language learning (SDLL) are 43.801, 33.864 and 10.78, indicating that a better model can be established by adding these three paths. Therefore, after adding the three paths, the modified structural model (Figure 2$)$ yielded a better fit $\left(\mathrm{X}^{2} / \mathrm{df}=2.616<3\right.$, $\mathrm{GFI}=0.908>0.90, \mathrm{CFI}=0.991>0.90, \mathrm{RMSEA}=0.079<0.08$, SRMR $=0.0154<0.06)$.

According to Table 5, except teacher capacity supports (TCS) $\rightarrow$ technological self-efficacy (SE), teacher affective supports (TAS) $\rightarrow$ perceived usefulness (PU), teacher capacity supports (TCS) $\rightarrow$ perceived usefulness $(\mathrm{PU})$, teacher behavior supports (TBS) $\rightarrow$ perceived usefulness (PU), the standardized path coefficient of the other paths is not close to or greater than 1, and the parameter estimation SE value is greater than 0 , indicating that the parameters of the structural 
TABLE 2 | Correlations among study variables.

\begin{tabular}{|c|c|c|c|c|c|c|c|}
\hline Variables & PU & PEU & TAS & TCS & TBS & SE & SDLL \\
\hline PEU & $0.688^{\star \star}$ & $(0.740)$ & & & & & \\
\hline TCS & $0.561^{\star *}$ & $0.648^{\star \star}$ & $0.826^{\star \star}$ & $(0.821)$ & & & \\
\hline TBS & $0.340^{\star \star}$ & $0.424^{\star \star}$ & $0.647^{\star \star}$ & $0.672^{\star *}$ & $(0.826)$ & & \\
\hline SE & $0.564^{\star \star}$ & $0.725^{\star \star}$ & $0.558^{\star \star}$ & $0.524^{\star \star}$ & $0.473^{\star \star}$ & $(0.817)$ & \\
\hline
\end{tabular}

N = 197. PU, perceived usefulness; PEU, perceived ease of use; TAS, teacher affective supports; TCS, teacher capacity supports; TBS, teacher behavior supports; SE, technological self-efficacy; SDLL, self-directed language learning. Diagonal in parentheses: square root of average variance extracted from observed variables (items). ${ }^{* *} p<0.01$.

TABLE 3 | The convergent and discriminant validity of the measurement model.

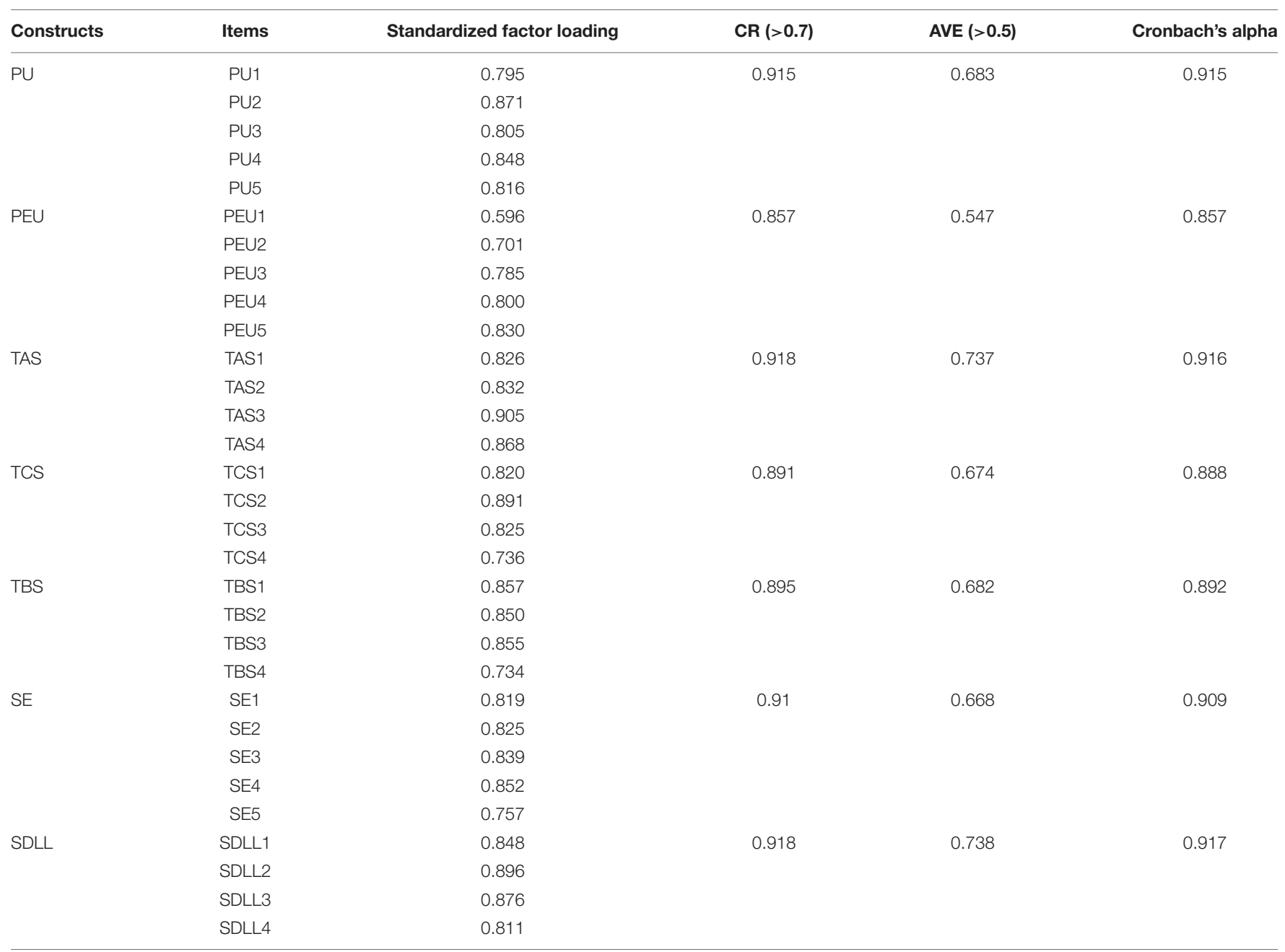

model are reasonable; the CR critical value is greater than 2 , and the $p$ value is significant under the level of 0.005 , indicating that the parameters of the structural model are significant.

\section{Assessment of Mediating Paths}

Table 6 presented that TAS $\rightarrow$ PU $\rightarrow$ SDLL, TAS $\rightarrow$ SE $\rightarrow$ SDLL and TCS $\rightarrow$ PU $\rightarrow$ SDLL had total mediating effects. In addition, TBS $\rightarrow$ SE $\rightarrow$ SDLL had partial mediating effects. As such, it can be found that perceived usefulness (PU) and technological self-efficacy (SE) mediated the relationship between teacher supports and self-directed language learning (SDLL) with a statistically significant 95\% confidence interval (CI) values. According to the guidelines by Cohen (1988), effect sizes with values less than 0.1 are considered small, those with 
TABLE 4 | Comparison of fitting test value and fitting standard value of the modified hypothesis model.

\begin{tabular}{|c|c|c|c|c|c|}
\hline & CMIN/DF & GFI & CFI & RMSEA & SRMR \\
\hline Fitting standard value & $<3$ is good & $>0.9$ & $>0.9$ & $<0.08$ is good & $<0.06$ \\
\hline Unrevised model & 25.212 & 0.816 & 0.836 & 0.351 & 0.1144 \\
\hline Added: SE $\rightarrow$ PEU & 14.126 & 0.915 & 0.926 & 0.259 & 0.0812 \\
\hline Added: PU $\rightarrow$ PEU & 5.640 & 0.969 & 0.979 & 0.154 & 0.0427 \\
\hline Added: TBS $\rightarrow$ SDLL & 2.616 & 0.989 & 0.995 & 0.079 & 0.0154 \\
\hline
\end{tabular}

CMIN/DF, Chi-square/Degrees of freedom.

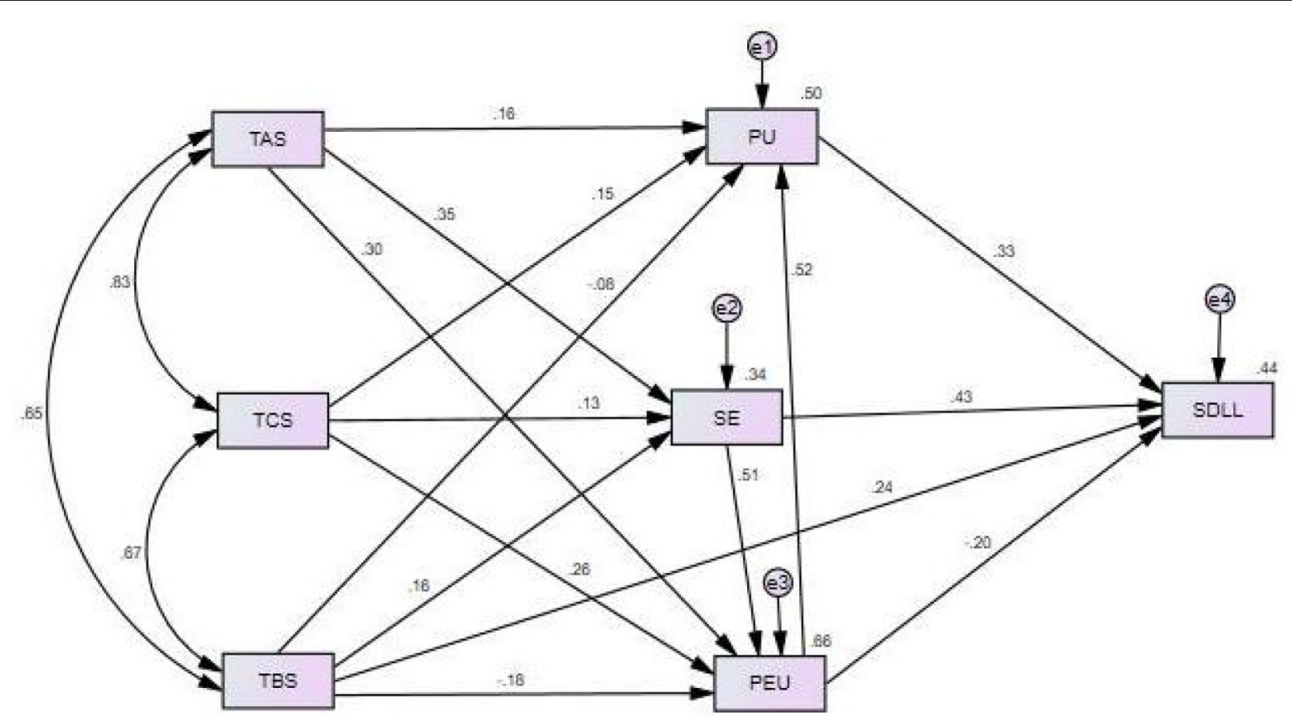

FIGURE 2 | The modified model.

less than 0.3 are medium, and values with 0.4 or more are considered large. The results of the mediation analysis shown in Table 6 indicated statistically significance and accorded with the guidelines by Cohen $(1988)$ with small to medium $(0.079<0.178)$ indirect effect values.

\section{DISCUSSION}

Currently, technology is increasingly utilized in Chinese classrooms. This increase in technology access lessens external barriers known as first-order barriers (Kopcha, 2012). Previous studies which have primarily focused on teachers' technological integration into pedagogical instructions found that technology access does not automatically equate to high efficiency of technology usage (Ertmer and Ottenbreit-Leftwich, 2010) and that teachers are still limited in facilitating students' technologybased learning (Buabeng-Andoh, 2012). Thereby, the role value on teachers' internalization of external barriers and externalization of personal beliefs for technology integration was highlighted (Vongkulluksn et al., 2018), and more importantly, "it is essential that we not only focus on what teachers could do with technologies inside the classroom but also explore how teachers could help maximize the potentials of technology for learning by enhancing the quantity and quality of learner self-directed use of technology for learning outside the classroom" (Lai, 2015, p. 80).

The present study investigated the mediating roles of internal factors linking teachers' various supports to students' selfdirected language learning. Specifically, the study constructed a multiple mediation model to examine the mediating roles of perceived usefulness, perceived easy of use and technological self-efficacy in the associations between teacher supports and students' self-directed language learning. The results demonstrated that three categories of teacher supports influenced the development of mediating factors (i.e., perceived usefulness, perceived easy of use and technological self-efficacy) which subsequently linked to students' self-directed language learning. These findings extended previous researches by considering both the internal factors (i.e., perceived usefulness, perceived easy of use and technological self-efficacy) and external factors (i.e., teacher supports) of influencing students' self-directed language learning. Consistent with previous study, the path analysis revealed that teacher supports, especially teacher behavior supports, were directly associated with students' self-directed language learning (Lai, 2015). Specifically, students who perceive teachers' behavior supports such as teachers' encouragement to use technology resources tend to conduct more self-directed language learning beyond the classroom. The path analysis of this study also indicated that the other two teacher supports (i.e., 
TABLE 5 | The path analysis.

\begin{tabular}{|c|c|c|c|c|c|}
\hline Path & Path coefficient & S. E. & C. $R$. & $P(<0.05)$ & Results \\
\hline $\mathrm{TCS} \rightarrow \mathrm{SE}$ & 0.137 & 0.116 & 1.189 & 0.234 & Not support \\
\hline $\mathrm{TAS} \rightarrow \mathrm{SE}$ & 0.359 & 0.110 & 3.261 & 0.001 & Support \\
\hline $\mathrm{TBS} \rightarrow \mathrm{SE}$ & 0.160 & 0.079 & 2.020 & 0.043 & Support \\
\hline $\mathrm{TBS} \rightarrow \mathrm{PEU}$ & -0.158 & 0.050 & -3.141 & 0.002 & Support \\
\hline $\mathrm{TAS} \rightarrow \mathrm{PEU}$ & 0.271 & 0.071 & 3.828 & 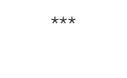 & $\begin{array}{l}\text { Strongly } \\
\text { support }\end{array}$ \\
\hline $\mathrm{TCS} \rightarrow \mathrm{PEU}$ & 0.238 & 0.073 & 3.281 & 0.001 & support \\
\hline $\mathrm{SE} \rightarrow \mathrm{PEU}$ & 0.446 & 0.045 & 9.988 & 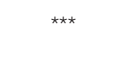 & $\begin{array}{l}\text { Strongly } \\
\text { support }\end{array}$ \\
\hline $\mathrm{TAS} \rightarrow \mathrm{PU}$ & 0.162 & 0.100 & 1.613 & 0.107 & Not support \\
\hline $\mathrm{TCS} \rightarrow \mathrm{PU}$ & 0.159 & 0.102 & 1.560 & 0.119 & Not support \\
\hline $\mathrm{TBS} \rightarrow \mathrm{PU}$ & -0.082 & 0.068 & -1.197 & 0.231 & Not support \\
\hline $\mathrm{PEU} \rightarrow \mathrm{PU}$ & 0.587 & 0.080 & 7.381 & 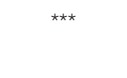 & $\begin{array}{l}\text { Strongly } \\
\text { support }\end{array}$ \\
\hline $\mathrm{PU} \rightarrow \mathrm{SDLL}$ & 0.377 & 0.084 & 4.497 & 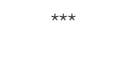 & $\begin{array}{l}\text { Strongly } \\
\text { support }\end{array}$ \\
\hline $\mathrm{SE} \rightarrow \mathrm{SDLL}$ & 0.486 & 0.091 & 5.373 & 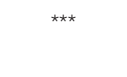 & $\begin{array}{l}\text { Strongly } \\
\text { support }\end{array}$ \\
\hline PEU $\rightarrow$ SDLL & -0.255 & 0.119 & -2.141 & 0.032 & Support \\
\hline TBS $\rightarrow$ SDLL & 0.265 & 0.068 & 3.901 & 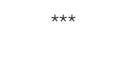 & $\begin{array}{l}\text { Strongly } \\
\text { support }\end{array}$ \\
\hline
\end{tabular}

Path coefficient $=$ standardized path coefficient. ${ }^{* * *} p<0.001$.

teacher affective supports and teacher capacity supports) didn't exert the direct influence on but affected students' self-directed language learning as the mediating factors. Affective support and capacity support such as encouragement, the recommendations of learning resources and the instructions of metacognitive strategies are the responsibilities of teachers that have been found to be largely unaware of Toffoli and Sockett (2015). Additionally, the multiple mediating model indicated how the teacher supports indirectly influenced students' self-directed language learning through the mediating role of students' perceived usefulness, perceived easy of use and technological self-efficacy. Thus, an implication of the results for professional development initiatives is that teacher supports need to be highlighted as: (1) undertaking teachers' responsibilities of facilitating students' willingness and capacities for technology-based learning in and beyond the classroom; (2) providing scaffolding mechanisms of supporting students' self-directed use of technology for learning outside the classroom (Reinders, 2010); and (3) incarnating teachers' capacity of maximizing the potentials of technology for education.

\section{The Mediating Role of Technology Acceptance}

The results of this study revealed that perceived usefulness mediated the relationship between teacher supports and students' self-directed language learning. According to the mediating paths, perceived usefulness totally mediated the relationship between teacher affective supports and students' self-directed language learning as well as the relationship between teacher capacity supports and students' self-directed language learning. The former mediating path coincided with the previous study which considered verbal persuasion or affective support as an important antecedent to induce people's behavioral changes through their positive attitudinal changes (Petty and Cacioppo, 1986). Lai (2015) identified that teacher affective supports could predict self-directed technology use by improving students' perceived usefulness. Therefore, teachers' affective supports such as oral persuasion and encouragement can induce students' behavioral changes such as changing their self-directed language learning behaviors through students' positive attitudinal changes (e.g., their perceived usefulness). The latter mediating path revealed that perceived usefulness had the mediating influence on the relationship between teacher capacity supports and students' self-directed language learning, which is also accordance with the previous study (Lai, 2015). Additionally, the mediating role of perceived usefulness between teacher capacity support and students' self-directed language learning corroborated previous studies concerning the role value of teacher capacity by: (1) improving students' awareness of usefulness for the behavior (Xia and Lee, 2000); (2) strengthening students' willingness to use variety of and potentials of technological resources to learn the language outside the classroom (Gamble et al., 2012); and (3) facilitating students to learn language more positively and independently after class (Lai, 2015). For instance, teachers' capacity behaviors such as providing in locating, selecting and using appropriate technological resources had indirect influence on their behaviors by changing students' behavioral intentions (McLoughlin and Lee, 2010; Lai et al., 2016). Students may enhance their perceived usefulness of technology and increase the frequency of self-directed language learning outside the classroom on the condition that teachers offer students capacity supports.

The results of this study found no noticeable mediating functions of perceived easy of use between teacher supports and students' self-directed language learning and supported the hypotheses by previous researches (e.g., Davis, 1989; Venkatesh et al., 2003; Lai et al., 2012) which confirmed that perceived easy of use didn't have direct effects on user's behavioral intention but indirectly influenced user's intentions to use technology through perceived usefulness. Students' self-directed language learning can be facilitated by directly enhancing their perceived usefulness and indirectly strengthening their perceived easy of use. In this study, according to the path analysis of teacher affective supports to perceived easy of use, teacher affective supports strongly promoted perceived easy of use, which verified the previous study that teachers' verbal persuasion or oral encouragement had the positive influence on students' perceived easy of use because teachers are the critical pedagogical examples and agents that shape students' awareness to use technology (Reinders, 2010; Toffoli and Sockett, 2015). Thus, this study echoed the view of Teo and Noyes (2014) that "technology providers ensured the ease of use of media which are targeted at teaching and learning in order to attract more educational users" (p. 62).

\section{The Mediating Role of Technological Self-Efficacy}

The study also documented that both teacher affective supports and teacher behavioral supports could relate to students' 
TABLE 6 | The mediating paths.

\begin{tabular}{|c|c|c|c|c|c|c|c|}
\hline Items & $\begin{array}{l}\text { C total } \\
\text { effects }\end{array}$ & $\mathbf{a}$ & b & $\begin{array}{c}\text { a } \times \text { b mediating } \\
\text { effects }\end{array}$ & $\begin{array}{c}\text { a x b }(95 \% \\
\text { Boot } \mathrm{Cl})\end{array}$ & $\begin{array}{c}\text { C' } \\
\text { direct effects }\end{array}$ & Results \\
\hline $\mathrm{TAS} \rightarrow \mathrm{PU} \rightarrow \mathrm{SDLL}$ & -0.002 & $0.415^{\star \star}$ & $0.379^{\star \star}$ & 0.157 & $0.043 \sim 0.232$ & -0.232 & Total mediating effects \\
\hline $\mathrm{TAS} \rightarrow \mathrm{PEU} \rightarrow \mathrm{SDLL}$ & -0.002 & $0.431^{\star \star}$ & -0.244 & -0.105 & $-0.195 \sim 0.008$ & -0.232 & No significant mediating effects \\
\hline $\mathrm{TAS} \rightarrow \mathrm{SE} \rightarrow \mathrm{SDLL}$ & -0.002 & $0.359^{\star \star}$ & $0.496^{\star \star}$ & 0.178 & $0.014 \sim 0.325$ & -0.232 & Total mediating effects \\
\hline $\mathrm{TCS} \rightarrow \mathrm{PU} \rightarrow \mathrm{SDLL}$ & $0.345^{\star}$ & $0.335^{\star \star}$ & $0.379^{\star \star}$ & 0.127 & $0.022 \sim 0.223$ & 0.223 & Total mediating effects \\
\hline $\mathrm{TCS} \rightarrow \mathrm{PEU} \rightarrow \mathrm{SDLL}$ & $0.345^{*}$ & $0.299^{\star \star}$ & -0.244 & -0.073 & $-0.150 \sim 0.006$ & 0.223 & No significant mediating effects \\
\hline $\mathrm{TCS} \rightarrow \mathrm{SE} \rightarrow \mathrm{SDLL}$ & $0.345^{\star}$ & 0.137 & $0.496^{\star \star}$ & 0.068 & $-0.059 \sim 0.165$ & 0.223 & No significant mediating effects \\
\hline $\mathrm{TBS} \rightarrow \mathrm{PU} \rightarrow \mathrm{SDLL}$ & $0.310^{\star \star}$ & -0.132 & $0.379^{\star *}$ & -0.05 & $-0.116 \sim 0.005$ & $0.259^{\star \star}$ & No significant mediating effects \\
\hline $\mathrm{TBS} \rightarrow \mathrm{PEU} \rightarrow \mathrm{SDLL}$ & $0.310^{\star \star}$ & -0.086 & -0.244 & 0.021 & $-0.014 \sim 0.067$ & $0.259^{\star *}$ & No significant mediating effects \\
\hline $\mathrm{TBS} \rightarrow \mathrm{SE} \rightarrow \mathrm{SDLL}$ & $0.310^{\star \star}$ & $0.160^{*}$ & $0.496^{\star \star}$ & 0.079 & $-0.003 \sim 0.160$ & $0.259^{\star *}$ & Partial mediating \\
\hline
\end{tabular}

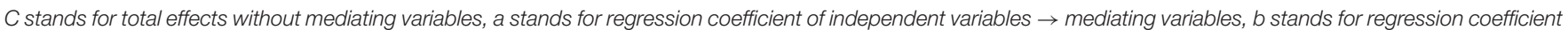
of mediating variables $\rightarrow$ dependent variables, $c^{\prime}$ stands for regression coefficient with mediating variables (i.e., direct mediating effect) of independent variables $\rightarrow$ dependent variables, ${ }^{*} P<0.05 ;{ }^{*} P<0.01$.

self-directed language learning through the mediating role of technological self-efficacy. According to Henry (2013), perceived social support had a significant influence on technological outcome expectations and interests. What's more, technological self-efficacy had strong associations with technological expectations and interests (Sheu et al., 2010). Fishbein et al. (1980) conceptualized that verbal persuasion or affective support was the fundamental element for individuals' attitudinal beliefs and confidence. Technological self-efficacy which standards for individuals' intentions and beliefs to use technology was considered as the vital determinant of the behavior of using the technology (Hall and Higgins, 2005; Ma et al., 2005; Teo, 2009; Teo and van Schaik, 2012; Moftakhari, 2013). On a similar note, Scherer et al. (2019) held that an individual is more likely to use technology if he/she has higher technological self-efficacy. To be specific, students with teacher affective supports may have stronger attitudinal beliefs and technological self-efficacy. Moreover, they may better cope with their self-directed language learning outside the classroom. Besides, in this study, the results indicated that teacher behavioral supports indirectly influenced students' self-directed language learning through the mediating role of technological self-efficacy. This finding is consistent with Ertmer (2005) in that teacher behavioral supports could give students opportunities to observe the teacher and other peers on how to use technology to assist language learning. Lai (2015) pointed out that teacher behavior supports could give students ideas of possible useful technological resources in self-directed language learning. By absorbing and learning teachers' or peers' technological experiences, it is possible for students to enhance their confidence and technological self-efficacy which may exert advantageous influence on learning language independently beyond the classroom. Thus, it might be useful if, in the teaching process, teachers offer affective or behavioral supports to help build up students' technological self-efficacy.

\section{Implications and Limitations}

The present study theoretically established a solid foundation for the compensatory model of teacher supports toward selfdirected language learning based on the university students' sample of primarily highly engaged language learners and covered the internal factors of their technology acceptance and technological self-efficacy. From a practical point of view, the implications of this study can be depicted as follows: (1) enhancing a deeper understanding of students' utilization of technology for language learning; (2) serving as a useful guidance on the development of intervention programs where teachers could optimize their potential roles in supporting students' technology-based self-directed language learning beyond the classroom; and (3) reducing the number of obstacles posed in online learning by shifting students' maladaptive obsessive engagement to self-determined engagement through teacher supports and the stimulation of students' psychological factors.

Despite this study adopted rigorous procedures, there existed limitations. First of all, the results of this study were grounded on a comparatively small sample, which may give rise to a potential bias that will affect the degree to which these results are generalizable. The future study may entail involving a larger sample to include different types of student participants. Secondly, the simplex cross-sectional design being applied in this study may result in a common method bias. Hence, it is suggested that future study adopt multi-layered, multidimensional methods (e.g., the combination of cross-sectional design with longitudinal research) to enhance our understanding of the causality as far as possible.

\section{CONCLUSION}

This study aimed to explore the contributions of teacher supports to students' self-directed language learning and investigate whether three variables (i.e., perceived usefulness, perceived easy of use and technological self-efficacy) mediated these associations. The findings of this study indicated that teacher supports influenced students' self-directed language learning mainly through perceived usefulness and technological selfefficacy while perceived easy of use had indirect mediating functions by directly influencing perceived usefulness. Thus, there was evidence from this study to suggest the significance 
of elevating teachers' awareness of the substantial supports in establishing and enhancing students' perceived easy of use, perceived usefulness and technological self-efficacy so that students are highly motivated to conduct self-directed language learning beyond the classroom. This study also suggested that the improvement of students' technology-based self-directed language learning may be most feasible by promoting beneficial harmonious engagement through teacher supports and the stimulation of students' psychological factors. Against the background of technology integration redefining teacher-student interactions in the teaching landscapes, the results of this study would inform that the future research on teachers' compliance in relation to technology use be converted from institutional mandates into teachers' conscientious behaviors.

\section{AUTHOR'S NOTE}

$\mathrm{XP}$ is an associate professor in Xingzhi College, Zhejiang Normal University, Jinhua, China. His research interests are English Language teachers' technology use for professional development and students' learning, intercultural English education and educational psychology. His publications have appeared in International Journal of Computer-assisted Language Learning and Teaching, and Social Behavior and Personality, and Frontiers in Psychology. WC is a postgraduate student in College of Foreign Languages, Zhejiang Normal University, Jinhua, China. Her research interests are second language acquisition and technology-based self-directed learning.

\section{REFERENCES}

Abali Ozturk, Y., and Sahin, C. (2015). Determining the relationships between academic achievement, self-efficacy and attitudes towards maths. J. Acad. Soc. Sci. Stud. 31, 343-366.

Ajzen, I. (2002). Perceived behavioral control, self-efficacy, locus of control, and the theory of planned behavior. J. Appl. Soc. Psychol. 32, 665-683. doi: 10.1111/ j.1559-1816.2002.tb00236.x

Arbaugh, J. B. (2000). Virtual classroom characteristics and student satisfaction with Internet-based MBA courses. J. Manag. Educ. 24, 32-54.

Bailly, S. (2011). “Teenagers learning language out of school: What, why and how do they learn? How can school help them?" in Beyond The Language Classroom, eds P. Benson and H. Reinders (Basingstoke: Palgrave Macmillan), 119-131. doi: 10.1044/0161-1461(2008/037)

Bandura, A. (1997). Self-Efficacy: The Exercise of Control. New York, NY: Freeman.

Bassi, M., Steca, P., Delle Fave, A., and Caprara, G. V. (2007). Academic self-efficacy beliefs and quality of experience in learning. J. Youth Adolesc. 36, 301-312. doi: 10.1007/s10964-006-9069-y

Buabeng-Andoh, C. (2012). Factors influencing teachers' adoption and integration of information and communication technology into teaching: a review of the literature. Int. J. Educ. Dev. Using Inf. Commun. Technol. 8, 136-155.

Carson, L., and Mynard, J. (2012). "Introduction," in Advising in Language Learning: Dialogue, Tools and Context, eds J. Mynard and L. Carson (Harlow: Pearson Education Limited), 3-25.

Celik, V., and Yesilyurt, E. (2013). Attitudes to technology, perceived computer self-efficacy and computer anxiety as predictors of computer supported education. Comput. Educ. 60, 148-158. doi: 10.1016/j.compedu.2012.06.008

\section{DATA AVAILABILITY STATEMENT}

The original contributions presented in the study are included in the article/supplementary material, further inquiries can be directed to the corresponding author/s.

\section{ETHICS STATEMENT}

Ethical review and approval was not required for the study on human participants in accordance with the local legislation and institutional requirements. Written informed consent for participation was not required for this study in accordance with the national legislation and the institutional requirements.

\section{AUTHOR CONTRIBUTIONS}

XP conceived, designed, and executed the study, collected the data, wrote the manuscript, and revised the final version of the manuscript. WC analyzed the data and participated in writing and revising the manuscript. Both authors have read and approved the submitted version.

\section{FUNDING}

This work was funded by Humanities and Social Sciences Research Project of the Ministry of Education of the People's Republic of China (Grant No. 20YJC740047).

Chen, P. (2018). "Research on sharing economy and e-learning in the era of "Internet plus"," in Paper Presented in 2nd International Conference on Education Science and Economic Management (ICESEM 2018), (Amsterdam: Atlantis Press). doi: 10.2991/icesem-18.2018.173

Cho, M.-H., and Kim, J. (2013). Students' self-regulation for interaction with others in online learning environments. Internet High. Educ. 1, 69-75. doi: 10.1016/j. iheduc.2012.11.001

Clark, W., Logan, K., Luckin, R., Mee, A., and Oliver, M. (2009). Beyond WLLA 2.0: mapping the technology landscapes of young learners. J. Comput. Assist. Learn. 25, 56-69. doi: 10.1111/j.1365-2729.2008.00 305.x

Cohen, A. D., and White, C. (2008). "Language learners as informed consumers of language instruction," in Studies in Language and Language Education: Essays in Honour of Elite Olshtain, eds A. Stavans and I. Kupferberg (Jerusalem: The Hebrew University Magnes Press), 185-205.

Cohen, J. (1988). Statistical Power Analysis for the Behavioral Sciences, 2nd Edn. Hillsdale: Erlbaum.

Davis, F. D. (1989). Perceived usefulness, perceived ease of use, and user acceptance of information technology. MIS Q. 13, 319-339. doi: 10.2307/24 9008

Davis, H. A. (2003). Conceptualizing the role and influence of student-teacher relationships on children's social and cognitive development. Educ. Psychol. 38, 207-234. doi: 10.1207/s15326985ep3804_2

Deepwell, F., and Malik, S. (2008). On campus, but out of class: an investigation into students' experiences of learning technologies in their self-directed study. Res. Learn. Technol. 16, 5-14.

Ertmer, P. A. (2005). Teacher pedagogical beliefs: the final frontier in our quest for technology integration?. Educ. Technol. Res. Dev. 53, 25-39. doi: 10.1007/ bf02504683 
Ertmer, P. A., and Ottenbreit-Leftwich, A. T. (2010). Teacher technology change: how knowledge, confidence, beliefs, and culture intersect. J. Res. Technol. Educ. 42, 255-284.

Ertmer, P. A., Ottenbreit-Leftwich, A. T., Sadik, O., Sendurur, E., and Sendurur, P. (2012). Teacher beliefs and technology integration practices: a critical relationship. Comput. Educ. 59, 423-435. doi: 10.1186/s12913-0161423-5

Fagerlund, T. (2012). Learning and Using English and Swedish Beyond The Classroom: Activity Systems of Six Upper Secondary School Students. Ph.D. thesis. Finland: University of Jyvaskyla.

Farmer, T. W., Lines, M. M., and Hamm, J. V. (2011). Revealing the invisible hand: the role of teachers in children's peer experiences. J. Appl. Dev. Psychol. 32, 247-256. doi: 10.1016/j.appdev.2011.04.006

Fishbein, M., and Ajzen, I. (1975). Belief, attitude, intention, and behavior: an introduction to the theory and research. Philos. Rhetor. 10, $130-132$.

Fishbein, M., Ajzen, I., and McArdle, J. (1980). "Changing the behavior of alcoholics: Effects of persuasive communication," in Understanding Attitudes And Predicting Social Behavior, eds I. Ajzen and M. Fishbein (Englewood Cliffs: Prentice-Hall), 217-242.

Gallivan, M. J., Spitler, V. K., and Koufaris, M. (2005). Does information technology training really matter? A social information processing analysis of coworkers' influence on IT usage in the workplace. J. Manag. Inf. Syst. 22, 153-192. doi: 10.1080/07421222.2003.11045830

Gamble, C., Aliponga, J., Wilkins, M., Koshiyama, Y., Yoshida, K., and Ando, S. (2012). "Examining learner autonomy dimensions: students' perceptions of their responsibility and ability," in JALT2011 Conference Proceedings, eds A. Stewart and N. Sonda (Tokyo: JALT), 263-272.

Garrison, D. R. (1997). Self-directed learning: toward a comprehensive model. Adult Educ. Q. 48, 18-33. doi: 10.1177/0741713697048 00103

Garrison, D. R., and Akyol, Z. (2009). Role of instructional technology in the transformation of higher education. J. Comput. High. Educ. 21, 19-30.

Gray, K., Chang, S., and Kennedy, G. (2010). Use of social wLLA technologies by international and domestic undergraduate students: implications for internationalising learning and teaching in Australian universities. Technol. Pedagogy Educ. 19, 31-46. doi: 10.1080/147593909035 79208

Hagger, M. S., and Chatzisarantis, N. L. D. (2012). Transferring motivation from educational to extramural contexts: a review of the trans-contextual model. Eur. J. Psychol. Educ. 27:1952012. doi: 10.1007/s10212-011-0082-5

Hair, J. F. Jr., Black, W. C., Babin, B. J., and Anderson, R. E. (2010). Multivariate Data Analysis: A Global Perspective, 7th Edn. London: Pearson.

Hall, I., and Higgins, S. (2005). Primary school students' perceptions of interactive whiteboards. J. Comput. Assist. Learn. 21, 102-112. doi: 10.1111/j.1365-2729. 2005.00118.x

Hao, S., Dennen, V. P., and Mei, L. (2017). Infuential factors for mobile learning acceptance among Chinese users. Educ. Technol. Res. Dev. 65, 101-123. doi: 10.1007/s11423-016-9465-2

Hayes, A. F. (2013). Introduction to Mediation, Moderation, and Conditional Process Analysis: A Regression-Based Approach. New York, NY: Guilford Press.

Henry, A. (2013). "Digital games and ELT: Bridging the authenticity gap," in International Perspectives on Motivation: Language Learning And Professional Challenges, ed. E. Ushioda (London: Palgrave Macmillan), 133-155.

Hofstede, G. (2008). Culture's Consequences: Comparing Values, Behaviors, Institutions and Organizations Across Nations, 2nd Edn. Shanghai: Shanghai Foreign Language Education Press.

Hsieh, J. S. C., Huang, Y.-M., and Wu, W.-C. V. (2017). Technological acceptance of LINE in flipped EFL oral training. Comput. Hum. Behav. 70, 178-190. doi: 10.1016/j.chb.2016.12.066

Hsu, L. (2016). An empirical examination of EFL learners' perceptual learning styles and acceptance of ASR-based computer-assisted pronunciation training. Comput. Assist. Lang. Learn. 29, 881-900. doi: 10.1080/09588221.2015.1069747

Hu, L., and Bentler, P. M. (1999). Cutoff criteria for fit indexes in covariance structure analysis: conventional criteria versus new alternatives. Struct. Equ. Modeling 6, 1-55. doi: 10.1080/10705519909540118
Huang, F., Sánchez-Prieto, J. C., Teo, T., García-Pealvo, F. J., and Zhao, C. (2020). The influence of university students' learning beliefs on their intentions to use mobile technologies in learning: a study in china and Spain. Educ. Technol. Res. Dev. 68, 3547-3565. doi: 10.1007/s11423-020-09806-0

Huang, F., Teo, T., Sánchez-Prieto, J. C., García-Peñalvo, F. J., and Olmos-Migueláñez, S. (2019a). Cultural values and technology adoption: a model comparison with university teachers from China and Spain. Comput. Educ. 133, 69-81. doi: 10.1016/j.compedu.2019. 01.012

Huang, F., Teo, T., and Zhou, M. (2019b). Chinese students' intentions to use the internet-based technology for learning. Educ. Technol. Res. Dev. 68, 575-591.

Hubbard, P., and Romeo, K. (2012). "Diversity in learner training," in Computer Assisted Language Learning: Diversity in Research and Practice, ed. G. Stockwell (Cambridge: Cambridge University Press), 33-48.

Hung, M. L., Chou, C., Chen, C. H., and Own, Z. Y. (2010). Learner readiness for online learning: scale development and student perceptions. Comput. Educ. 55, 1080-1090. doi: 10.1016/j.compedu.2010.05.004

Imlawi, J., Gregg, D., and Karimi, J. (2015). Student engagement in course-based social networks: the impact of instructor credibility and use of communication. Comput. Educ. 88, 84-96.

Jansen, R. S., and Janssen, J. (2017). Validation of the self-regulated online learning questionnaire. J. Comput. High. Educ. 29, 6-27. doi: 10.1007/s12528-0169125-x

Jeyaraj, A., Rottman, J. W., and Lacity, M. C. (2006). A review of the predictors, linkages, and biases in IT innovation adoption research. J. Inf. Technol. 21, 1-23. doi: $10.1057 /$ palgrave.jit.2000056

Keengwe, J. (2007). Faculty integration of technology into instruction and students' perceptions of computer technology to improve student learning. J. Inf. Technol. Educ. 6, 169-180. doi: 10.28945/208

King, W. R., and He, J. (2006). A meta-analysis of the technology acceptance model. Inf. Manag. 43, 740-755. doi: 10.1016/j.im.2006.05.003

Kitsantas, A., and Zimmerman, B. J. (2009). College students' homework and academic achievement: the mediating role of self-regulatory beliefs. Metacogn. Learn. 4, 97-110. doi: 10.1007/s11409-008-9028-y

Knowles, M. S. (1989). The Making of an Adult Educator. San Francisco: JosseyBass.

Kopcha, T. J. (2012). Teachers' perceptions of the barriers to technology integration and practices with technology under situated professional development. Comput. Educ. 59, 1109-1112. doi: 10.1016/j.compedu.2012.05.014

Krouska, A., Troussas, C., and Sgouropoulou, C. (2021). Mobile game-based learning as a solution in COVID-19 era: modeling the pedagogical affordance and student interactions. Educ. Inf. Technol. doi: 10.1007/s10639-021-10672-3 [Online ahead of print]

Lai, C. (2013). A framework of developing self-directed technology use for language learning. Lang. Learn. Technol. 17, 100-122. doi: 10.1007/s13187-020-01 929-5

Lai, C. (2015). Modeling teacher's influence on learners' self-directed use of technology for language learning outside the classroom. Comput. Educ. 82, 74-83. doi: 10.1016/j.compedu.2014.11.005

Lai, C., and Gu, M. Y. (2011). Self-regulated out-of-class language learning with technology. Comput. Assist. Lang. Learn. 24, 317-335. doi: 10.1080/09588221. 2011.568417

Lai, C., Hu, X., and Lyu, B. (2018). Understanding the nature of learners' out-ofclass language learning experience with technology. Comp. Assist. Lang. Learn. 31, 114-143. doi: 10.1080/09588221.2017.1391293

Lai, C., Li, X., and Wang, Q. (2017). Students' perceptions of teacher impact on their self-directed language learning with technology beyond the classroom: cases of Hong Kong and U.S. Educ. Technol. Res. Dev. 65, 1105-1133. doi: 10.1007/s11423-017-9523-4

Lai, C., Shum, M., and Tian, Y. (2016). Enhancing learners' self-directed use of technology for language learning: the effectiveness of an online training platform. Comput. Assist. Lang. Learn. 29, 40-60. doi: 10.1080/09588221.2014. 889714

Lai, C., Wang, Q., and Lei, J. (2012). What factors predict undergraduate students' use of technology for learning: a case from Hong Kong. Comput. Educ. 59, 569-579. doi: 10.1016/j.compedu.2012.03.006 
Lai, C., Zhu, W. M., and Gong, G. (2014). Understanding the quality of out-of-class English learning. TESOL Q. 49, 278-308. doi: 10.1002/tesq.171

Liaw, S. S., and Huang, H. M. (2003). An investigation of user attitudes toward search engines as an information retrieval tool. Comput. Hum. Behav. 19:751. doi: 10.1016/s0747-5632(03)00009-8

Liaw, S. S., Huang, H. M., and Chen, G. D. (2007). Surveying instructor and learner attitudes toward e-learning. Comput. Educ. 4, 1066-1080. doi: 10.1016/ j.compedu.2006.01.001

Ma, W. K., Andersson, R., and Streith, K. O. (2005). Examining user acceptance of computer technology: an empirical study of student teachers. J. Comput. Assist. Learn. 21, 387-395. doi: 10.1111/j.1365-2729.2005.00 145.x

Margaryan, A., and Littlejohn, A. (2010). Repositories and communities at crosspurposes: issues in sharing and reuse of digital learning resources. J. Comput. Assist. Learn. 24, 333-347. doi: 10.1111/j.1365-2729.2007.00267.x

Marsh, H. W., Hau, K.-T., and Wen, Z. (2004). In search of golden rules: comment on hypothesis-testing approaches to setting cutoff values for fit indexes and dangers in overgeneralizing $\mathrm{Hu}$ and Bentler's (1999) findings. Struct. Equ. Modeling 11, 320-341. doi: 10.1207/s15328007sem1103_2

McLoughlin, C., and Lee, M. L. (2010). Personalized and self-regulated learning in the WLLA 2.0 era:International exemplars of innovative pedagogy using social software. Aust. J. Educ. Technol. 26, 28-43.

Mew, L., and Honey, W. H. (2010). Effects of computer self efficacy on the use and adoption of online social networking. Int. J. Virtual Communities Soc. Netw. 2, 18-34. doi: 10.4018 /jvcsn. 2010010102

Moftakhari, M. M. (2013). Evaluating E-Learning Readiness of Faculty of Letters of Hacettepe. Ph.D. thesis. Ankara: Hacettepe University.

Montgomery, D., Peck, E., and Vining, G. (2001). Introduction To Linear Regression Analysis, 3rd Edn. New York, NY: Wiley.

Moore, G. C., and Benbasat, I. (1991). Development of an Instrument to Measure the Perceptions of Adopting an Information Technology Innovation. Inf. Syst. Res. 2, 192-222. doi: 10.1287/isre.2.3.192

Pan, X. (2020). Technology Acceptance, Technological Self-Efficacy, and Attitude Toward Technology-Based Self-Directed Learning: learning Motivation as a Mediator. Front. Psychol. 11:564294. doi: 10.3389/fpsyg.2020.564294

Papakostas, C., Troussas, C., Krouska, A., and Sgouropoulou, C. (2021). User acceptance of augmented reality welding simulator in engineering training. Educ. Inf. Technol. doi: 10.1007/s10639-020-10 418-7 [Online ahead of print].

Petty, R. E., and Cacioppo, J. T. (1986). "The elaboration likelihood model of persuasion," in Communication And Persuasion, eds R. Petty and J. Cacioppo (New York, NY: Springer), 1-24. doi: 10.1007/978-1-4612-4964-1_1

Reinders, H. (2010). Towards a classroom pedagogy for learner autonomy: a framework of independent language learning skills. Aust. J. Teach. Educ. 35, $40-55$.

Reinders, H., and Darasawang, P. (2012). "Diversity in language support," in Computer-Assisted Language Learning: Diversity in Research and Practice, ed. G. Stockwell (Cambridge: Cambridge University Press), 49-70.

Reinders, H., and White, C. (2011). Learner autonomy and new learning environments. Lang. Learn. Technol. 15, 1-3.

Salleh, U. K. M., Zulnaidi, H., Rahim, S. S. A., Zakaria, A. R., and Hidayat, R. (2019). Role of self-directed learning and social networking sites in lifelong learning. Int. J. Instr. 12, 167-182. doi: 10.29333/iji.2019.12411a

Scherer, R., Siddiq, F., and Tondeur, J. (2019). The technology acceptance model (TAM): a meta-analytic structural equation modeling approach to explaining teachers' adoption of digital technology in education. Comput. Educ. 128, 13-35. doi: 10.1016/j.compedu.2018.09.009

Sheu, H., Lent, R. W., Brown, S., Miller, M., Hennessy, K., and Duffy, R. D. (2010). Testing the choice model of social cognitive career theory across Holland themes: a meta-analytic path analysis. J. Vocat. Behav. 76, 252-264. doi: 10.1016/ j.jvb.2009.10.015

Song, L. Y., and Hill, J. R. (2007). A conceptual model for understanding selfdirected learning in online environments. J. Interact. Online Learn. 6, 27-42.

Sprenger, D. A., and Schwaninger, A. (2021). Technology acceptance of four digital learning technologies (classroom response system, classroom chat, e-lectures, and mobile virtual reality) after three months' usage. Int. J. Educ. Technol. High. Educ. 18:8. doi: 10.1186/s41239-021-00243-4
Su, Y., Zheng, C., Liang, J.-C., and Tsai, C. C. (2018). Examining the relationship between English language learners' online self-regulation and their self-efficacy. Aust. J. Educ. Technol. 34, 105-121.

Sun, P. J. P., and Mei, B. (2020). Modeling preservice Chinese-as-a-second/foreignlanguage teachers' adoption of educational technology: a technology acceptance perspective. Comput. Assist. Lang. Learn. doi: 10.1080/09588221.2020. 1750430 [Epub ahead of print].

Sundqvist, P. (2011). "A possible path to progress: Out-of-school English language learners in Sweden," in Beyond the Language Classroom, eds P. Benson and H. Reinders (New York, NY: Palgrave Macmillan), 106-118. doi: 10.1057/ 9780230306790_9

Taylor, S., and Todd, P. A. (1995). Understanding information technology usage: a test of competing models. Inf. Syst. Res. 5, 91-108.

Teo, T. (2009). Modelling technology acceptance in education: a study of preservice teachers. Comput. Educ. 52, 302-312. doi: 10.1016/j.compedu.2008.08. 006

Teo, T. (2011). Factors influencing teachers' intention to use technology: model development and test. Comput. Educ. 57, 2432-2440. doi: 10.1186/s12911-0190751-x

Teo, T. (2015). Comparing pre-service and in-service teachers' acceptance of technology: assessment of measurement invariance and latent mean differences. Comput. Educ. 83, 22-31. doi: 10.1016/j.compedu.2014. 11.015

Teo, T., Milutinovic, V., and Zhou, M. (2016). Modelling Serbian preservice teachers' attitudes towards computer use: a SEM and MIMIC approach. Comput. Educ. 94, 77-88. doi: 10.1016/j.compedu.2015. 10.022

Teo, T., and Noyes, J. (2014). Explaining the intention to use technology among pre-service teachers: a multi-group analysis of the Unified Theory of Acceptance and Use of Technology. Interact. Learn. Environ. 22, 51-66. doi: 10.1080/10494820.2011.64 1674

Teo, T., and van Schaik, P. (2012). Understanding the intention to use technology by Preservice teachers: an empirical test of competing theoretical models. Int. J. Hum. Comput. Interact. 28, 178-188. doi: 10.1080/10447318.2011.58 1892

Toffoli, D., and Sockett, G. (2015). University teachers' perceptions of online informal learning of English (OILE). Comput. Assist. Lang. Learn. 28, 7-21. doi: 10.1080/09588221.2013.776970

Troussas, C., Krouska, A., and Sgouropoulou, C. (2021). Impact of social networking for advancing learners' knowledge in E-learning environments. Educ. Inf. Technol. 26, 4285-4305. doi: 10.1007/s10639-021-10 483-6

Venkatesh, V., and Bala, H. (2008). Technology acceptance model 3 and a research agenda on interventions. Decis. Sci. 39, 273-315. doi: 10.1111/j.1540-5915.2008. 00192.x

Venkatesh, V., and Davis, F. (2000). A theoretical extension of the technology acceptance model: four longitudinal field studies. Manag. Sci. 46, 186-204. doi: $10.1287 /$ mnsc.46.2.186.11926

Venkatesh, V., and Davis, F. D. (1996). A model of the antecedents of perceived case of use: development and test. Decis. Sci. 27, 451-481. doi: 10.1111/j.15405915.1996.tb00860.x

Venkatesh, V., Morris, M., Davis, G., and Davis, F. D. (2003). User-acceptance of information technology: toward a unified view. MIS Q. 27, 425-478. doi: $10.2307 / 30036540$

Vongkulluksn, V. W., Xie, K., and Bowman, M. A. (2018). The role of value on teachers' internalization of external barriers and externalization of personal beliefs for classroom technology integration. Comput. Educ. 118, 70-81. doi: 10.1016/j.compedu.2017.11.009

Wong, K. T., Teo, T., and Russo, S. (2012). Influence of gender and computer teaching efficacy on computer acceptance among Malaysian student teachers: an extended technology acceptance model. Aust. J. Educ. Technol. 28, 11901207.

Xia, W., and Lee, G. (2000). "The influence of persuasion, training and experience on user perceptions and acceptance of IT innovation," in Proceedings of the 21st International Conference on Information Systems, (Atlanta: Association for Information Systems), 371-384. 
Yesilyurt, E., Ulas, A. H., and Akan, D. (2016). Teacher self-efficacy, academic selfefficacy, and computer self-efficacy as predictors of attitude toward applying computer-supported education. Сотри. Нum. Behav. 64, 591-601. doi: 10. 1016/j.chb.2016.07.038

Yousafzai, S. Y., Foxall, G. R., and Pallister, J. G. (2007). Technology acceptance: a meta-analysis of the TAM: part 1. J. Model. Manag. 2, 251-280.

Zandi, P., Thang, S. M., and Krish, P. (2014). Teacher professional development through blogging: some preliminary findings. Procedia Soc. Behav. Sci. 118, 530-536. doi: 10.1016/j.sbspro.2014.02.072

Zimmerman, B. J. (1986). Becoming a self-regulated learner: which are the key subprocesses? Contemp. Educ. Psychol. 11, 307-313. doi: 10.1016/0361-476X(86) 90027-5

Zuffianò, A., Alessandri, G., Gerbino, M., Kanacri, B. P. L., Di Giunta, L., Milioni, M., et al. (2013). Academic achievement: the unique contribution of self-efficacy beliefs in self-regulated learning beyond intelligence, personality traits, and self-esteem. Learn. Individ. Differ. 23, 158-162. doi: 10.1016/j.lindif.2012.07.010
Conflict of Interest: The authors declare that the research was conducted in the absence of any commercial or financial relationships that could be construed as a potential conflict of interest.

Publisher's Note: All claims expressed in this article are solely those of the authors and do not necessarily represent those of their affiliated organizations, or those of the publisher, the editors and the reviewers. Any product that may be evaluated in this article, or claim that may be made by its manufacturer, is not guaranteed or endorsed by the publisher.

Copyright $\odot 2021$ Pan and Chen. This is an open-access article distributed under the terms of the Creative Commons Attribution License (CC BY). The use, distribution or reproduction in other forums is permitted, provided the original author(s) and the copyright owner(s) are credited and that the original publication in this journal is cited, in accordance with accepted academic practice. No use, distribution or reproduction is permitted which does not comply with these terms. 